\title{
Echocardiographic assessment of infants born to diabetic mothers
}

\author{
A K DEORARI, ${ }^{*}$ A SAXENA,$\dagger \mathrm{M}$ SINGH, ${ }^{*}$ AND S SHRIVASTAVA $\dagger$ \\ Departments of *Paediatrics and $†$ Cardiology, All India Institute of Medical Sciences, New Delhi, India
}

SUMMARY Echocardiography was carried out in 31 neonates (group 1) born to diabetic mothers and 37 control infants (group 2) matched for weight and gestational age. The interventricular septum was significantly thicker in group 1 babies (mean (SD) $4.77(1.4) \mathrm{mm}$ ) compared with those in group $2(2.5(0.7) \mathrm{mm})$; in eight it was more than $5 \mathrm{~mm}$, but had regressed in six over a period of three months. There was no significant difference between the two groups in the left ventricular internal dimension, right ventricular outflow tract, or size of the left atrium or the aorta. The left ventricular mass was significantly greater in infants born to diabetic mothers. The left ventricular contractility (judged by the percentage of shortening of the internal dimension and the ejection fraction) was significantly greater in group 1 . No evidence of left ventricular outflow obstruction was found on pulse Doppler echocardiography in group 1.

Infants born to diabetic mothers have an increased risk of developing congestive cardiac failure. ${ }^{1}$ Myocardial dysfunction (tachypnoea and tachycardia) may be caused by primary cardiac disease or secondary to hypoxia, polycythaemia, or metabolic disturbances. Echocardiographic studies in these infants show thickened $(>5 \mathrm{~mm})$ interventricular septums and thickening of the right and left ventricular free walls with disproportionate septal hypertrophy in $25-30 \%$ of cases. ${ }^{2-4}$

We carried out a prospective echocardiographic study of infants born to diabetic mothers and compared the results with those from normal newborn infants born at full term.

\section{Patients and methods}

Infants from 31 consecutive births to mothers with overt diabetes mellitus or gestational diabetes that took place at the All India Institute of Medical Sciences Hospital were studied prospectively. These patients were selected from the group of high risk pregnant women at our antenatal clinics. All the women were routinely screened for diabetes mellitus using fasting and postprandial blood glucose concentrations. The borderline cases were subjected to oral glucose tolerance tests. ${ }^{5}$ Insulin was given to all overtly diabetic mothers, but gestational diabetes was managed by dietary control alone.

A group of 37 infants matched for gestational age and born after uncomplicated delivery immediately preceding or following the index case, served as controls. None of the mothers of these infants had diabetes mellitus. Clinical examination did not show any congenital malformations.

All deliveries were attended by a paediatrician well versed in techniques of resuscitation. Apgar scoring at birth was recorded in all, and none of the babies had birth asphyxia. All babies who had uncomplicated deliveries were nursed with their mothers in the maternity ward. All infants born to overt or gestational diabetic mothers, and infants in the control group who were small for gestational age or large for gestational age were screened for hypoglycaemia at 1-2 hours, 6-8 hours, 24 hours, and 48 hours. Hypoglycaemia was treated according to the prevailing practice of our unit. ${ }^{6}$

Echocardiographic studies were performed using an ATL ultramark ' 8 ' system equipped with a combined cross sectional imaging and pulsed Doppler transducer using a $5 \mathrm{MHz}$ transducer, at a mean (SD) age of $3(1.5)$ days, and recordings made on video tape at a speed of $100 \mathrm{~mm} / \mathrm{s}$. Echocardiographic meaurements were made from these using standard techniques (figs 1 and 2). ${ }^{7}$ Doppler velocities were measured across mitral, tricuspid, pulmonary, and aortic valves and all infants were carefully screened for any gradient across the left ventricular outflow tract.

Left ventricular function was assessed by calcula- 


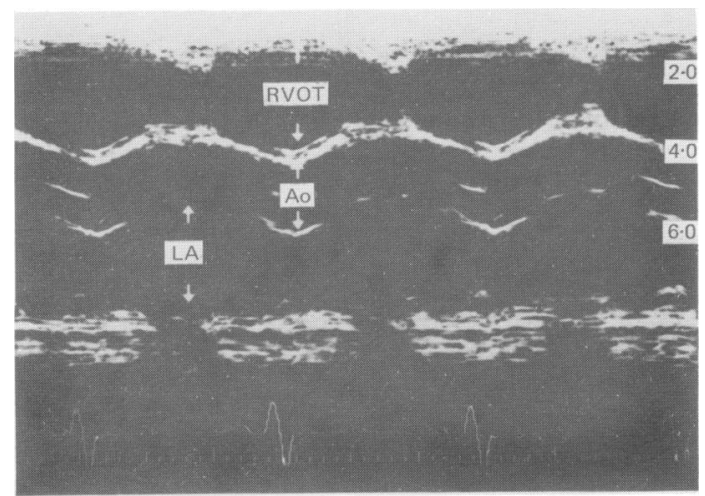

Fig $1 M$ mode echocardiogram showing aortic and right ventricular outflow tract dimensions at the end of diastole and left atrial dimension at the end of systole. $R V O T=$ right ventricular outflow tract, $A O=$ aorta, $L A=$ left atrium.

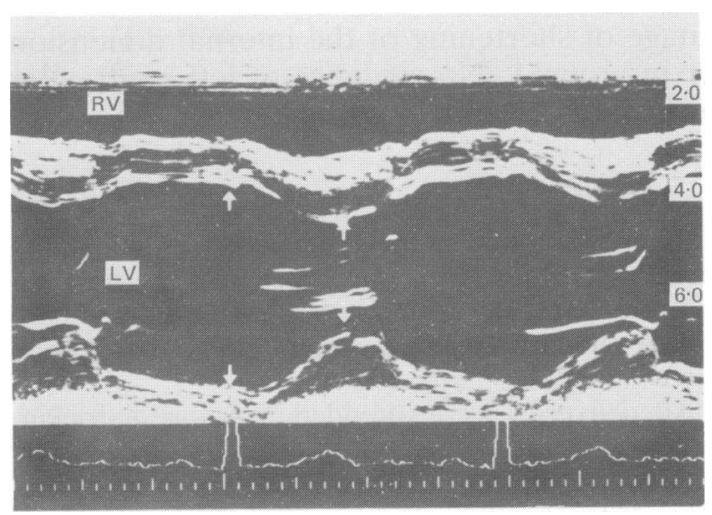

Fig $2 M$ mode echocardiogram showing left ventricular internal dimensions at the end of diastole and the end of systole. $R V=$ right ventricle, $L V=$ left ventricle.

ting the percentage shortening of the internal dimension $^{8}$ and the ejection fraction. ${ }^{7}$ The percentage shortening of the internal dimension equals the left ventricular internal dimension at the end of diastole minus that at the end of systole divided by the dimension at the end of diastole and multiplied by 100 . The ejection fraction is calculated by the same formula except that all values (except 100) are cubed.

The left ventricular mass was calculated by cubing the sum of the left ventricular internal dimension, the thickness of the interventricular septum and the thickness of the left posterior wall (all at the end of diastole), subtracting the cubed value for left ventricular internal dimension at the end of diastole, and multiplying by $1 \cdot 05 .{ }^{9}$

Septal hypertrophy was defined as a septal thick- ness of $5 \mathrm{~mm}$ or more. ${ }^{10}$ Newborn babies in whom the interventricular septum at the end of diastole measured $5 \mathrm{~mm}$ were followed up at four to six weeks, and at 3 months of age. Statistical analysis was by Student's $t$ test.

\section{Results}

Five babies were born to mothers with diabetes mellitus and 26 to mothers with gestational diabetes; there were 17 girls and 14 boys. Four were born at $<37$ weeks' gestation and 27 were born at full term. The mean (SD) gestational age was $38.2(1.5)$ weeks, range 35 to 40 . The mean weight was 3340 (79) g, and 10 infants were large for gestational age, two small, and 19 normal.

Thirty seven control infants ( 20 girls and 17 boys) were evaluated echocardiographically. Four were born at $<37$ weeks' gestation and 33 were born at full term. Their mean gestational age was $38.1(0.4)$ weeks, range 35 to 40 . Their mean weight was 3070 (43) g, with four infants large for gestational age and the rest normal.

The mean weight and gestational age were not significantly different in the two groups $(p>0 \cdot 05)$.

In normal control infants the mean thickness of the interventricular septum was $2.5(0.7) \mathrm{mm}$; even among those infants large for gestational age the thickest was $4.3 \mathrm{~mm}$. This infant weighed $4200 \mathrm{~g}$. By contrast in the infants born to diabetic mothers the mean thickness was $4.7(1.4) \mathrm{mm}(\mathrm{p}<0.001)$, and even in one infant who was small for gestational age, weighing only $2400 \mathrm{~g}$, the thickness was $7 \cdot 1 \mathrm{~mm}$. Eight infants $(25 \%)$ born to diabetic mothers had thicknesses of more than $5 \mathrm{~mm}$. The left ventricular posterior wall in systole was thicker in infants of diabetic mothers. Other echocardiographic dimensions were not significantly different between the two groups (table 1).

Left ventricular contractility as assessed by the ejection fraction and percentage shortening of the internal dimension was significantly higher in infants of diabetic mothers compared with the controls, and the left ventricular mass was significantly greater $(\mathrm{p}<0.001)$.

Doppler velocities were normal across all valves in both groups and there was no evidence of left ventricular outflow tract obstruction by Doppler even in patients with thickened septums.

Of the eight patients with thickened septums on initial examination, six were followed up by serial echocardiograms at four to six weeks and at 3 months. The septal thickness had decreased in all six to below $5 \mathrm{~mm}$. This was noticed within six weeks in four and within three months in the other two infants. 
Table 1 Mean (SD) echocardiographic measurements in infants of diabetic mothers and controls

\begin{tabular}{|c|c|c|c|}
\hline & $\begin{array}{l}\text { Infants of } \\
\text { diabetic } \\
\text { mothers } \\
(n=31)\end{array}$ & $\begin{array}{l}\text { Control } \\
\text { infants } \\
(n=37)\end{array}$ & p Value \\
\hline \multicolumn{4}{|l|}{ Left ventricular internal dimension $(\mathrm{mm})$ : } \\
\hline At the end of diastole & $15 \cdot 1 \quad(2 \cdot 6)$ & $(2 \cdot 2)$ & NS \\
\hline At the end of systole & $8.8 \quad(1.8)$ & $8.5 \quad(1.5)$ & NS \\
\hline \multicolumn{4}{|l|}{ Thickness of interventricular septum $(\mathrm{mm})$ : } \\
\hline At the end of diastole & $4 \cdot 7 \quad(1.4)$ & $(0 \cdot 7)$ & $<0 \cdot 001$ \\
\hline At the end of systole & $6 \cdot 1 \quad(1 \cdot 8)$ & $(0 \cdot 8)$ & $<0 \cdot 001$ \\
\hline \multicolumn{4}{|l|}{ Thickness of left ventricular posterior wall $(\mathrm{mm})$ : } \\
\hline At the end of diastole & $2 \cdot 7 \quad(0 \cdot 7)$ & $2 \cdot 5 \quad(0 \cdot 7)$ & NS \\
\hline At the end of systole & $3.9 \quad(1 \cdot 0)$ & $(0 \cdot 7)$ & $<0 \cdot 001$ \\
\hline Diameter of aorta $(\mathrm{mm})$ & $9.2 \quad(1.4)$ & $(1 \cdot 6)$ & NS \\
\hline Width of left atrium (mm) & $8 \cdot 2 \quad(1 \cdot 8)$ & $(1.9)$ & NS \\
\hline Width of right ventricular outflow tract (mm) & $11.0 \quad(2 \cdot 4)$ & $9.9 \quad(1.9)$ & NS \\
\hline Interventricular septum:left ventricular posterior wall ratio & $1.79(0.45)$ & $1 \cdot 18(0 \cdot 36)$ & $<0 \cdot 001$ \\
\hline Percentage shortening of internal dimension & $43.88(8 \cdot 04)$ & $38 \cdot 22(6 \cdot 59)$ & $<0 \cdot 01$ \\
\hline Percentage ejection fraction & $81 \cdot 54(8.31)$ & $74 \cdot 53(8 \cdot 71)$ & $<0 \cdot 01$ \\
\hline Left ventricular mass $(\mathrm{g})$ & $8.41(3.97)$ & $4.15(1.81)$ & $<0 \cdot 001$ \\
\hline
\end{tabular}

Table 2 Mean (SD) echocardiographic measurements in infants of diabetic mothers with and without hypoglycaemia

\begin{tabular}{|c|c|c|c|c|c|}
\hline \multirow[b]{2}{*}{ Birth weight (g) } & \multicolumn{2}{|c|}{$\begin{array}{l}\text { Infants with } \\
\text { hypoglycaemia } \\
(n=7)\end{array}$} & \multicolumn{2}{|c|}{$\begin{array}{l}\text { Infants without } \\
\text { hypoglycaemia } \\
(n=24)\end{array}$} & \multirow{2}{*}{$\begin{array}{l}\text { p Value } \\
\text { NS }\end{array}$} \\
\hline & 3670 & $(730)$ & 3210 & $(790)$ & \\
\hline \multicolumn{6}{|l|}{ Left ventricular internal dimension $(\mathrm{mm})$ : } \\
\hline At the end of diastole & $15 \cdot 2$ & $(2 \cdot 6)$ & $16 \cdot 9$ & $(3 \cdot 0)$ & NS \\
\hline At the end of systole & $8 \cdot 5$ & $(1 \cdot 8)$ & $8 \cdot 9$ & $(1.9)$ & \\
\hline \multicolumn{6}{|l|}{ Thickness of interventricular septum (mm): } \\
\hline At the end of diastole & $4 \cdot 6$ & $(1 \cdot 5)$ & $4 \cdot 8$ & $(1 \cdot 2)$ & NS \\
\hline At the end of systole & $5 \cdot 8$ & $(1 \cdot 8)$ & $6 \cdot 2$ & $(1.9)$ & NS \\
\hline \multicolumn{6}{|l|}{ Thickness of left ventricular posterior wall $(\mathrm{mm})$ : } \\
\hline At the end of diastole & $2 \cdot 5$ & $(0 \cdot 6)$ & $3 \cdot 2$ & $(1 \cdot 0)$ & $<0 \cdot 05$ \\
\hline At the end of systole & $3 \cdot 8$ & $(0 \cdot 9)$ & $4 \cdot 0$ & $(1 \cdot 1)$ & NS \\
\hline Diameter of aorta (mm) & $8 \cdot 8$ & $(1 \cdot 5)$ & $9 \cdot 5$ & $(1 \cdot 4)$ & NS \\
\hline Width of left atrium (mm) & $8 \cdot 2$ & $(1.9)$ & $8 \cdot 2$ & $(1 \cdot 3)$ & NS \\
\hline Width of right ventricular outflow tract $(\mathrm{mm})$ & $10 \cdot 5$ & $(2 \cdot 3)$ & $11 \cdot 3$ & $(2 \cdot 4)$ & NS \\
\hline Interventricular septum:left ventricular posterior wall ratio & 1.57 & $(0 \cdot 48)$ & 1.86 & $(0 \cdot 43)$ & NS \\
\hline Percentage shortening of internal dimension & $44 \cdot 13$ & $(8 \cdot 01)$ & $43 \cdot 66$ & $(7 \cdot 64)$ & NS \\
\hline Percentage ejection fraction & 80.94 & $(12 \cdot 58)$ & $81 \cdot 50$ & $(6 \cdot 56)$ & NS \\
\hline Left ventricular mass $(\mathrm{g})$ & $9 \cdot 46$ & $(3 \cdot 07)$ & 8.06 & $(4 \cdot 23)$ & NS \\
\hline
\end{tabular}

Hypoglycaemia occurred in seven of 31 patients born to diabetic mothers $(23 \%)$ and in none in the control group. The various echocardiographic dimensions did not differ significantly in patients with or without hypoglycaemia except for the thickness of the left ventricular posterior wall at the end of diastole (table 2).

\section{Discussion}

Echocardiographic data in the present study substantiates the earlier radiographic and histopathological observations describing cardiomegaly in infants born to diabetic mothers. ${ }^{10}$ The thickness of the interventricular septum and left ventricular posterior wall thickness were greater than normal, and the ratio of one to the other was significantly more $(p<0.001)$ in infants born to diabetic mothers. This increased myocardial thickness cannot be explained merely by their being large for gestational age because in our series of normal controls, the myocardial thickness in the large babies never exceeded the upper limit of normal value. In addition a small infant born to a diabetic mother had a thickened septum. The left atrial and internal ventricular dimensions were comparable with the dimensions of the normal controls. The left ventricular mass was significantly greater in infants born to 
diabetic mothers compared with controls $(\mathrm{p}<0 \cdot 001)$, and in addition the ejection fraction and percentage shortening of the internal dimension were significantly increased $(p<0.001)$, indicating that despite having cardiac enlargement the contractility of the myocardium was enhanced.

Asymmetric septal hypertrophy was first observed in a stillborn infant of a diabetic mother by Maron et al. " Poor diabetic control has been correlated both with the degree of septal hypertrophy and with the presence of symptoms of respiratory distress. ${ }^{3}$ None of our newborns had respiratory distress or congestive heart failure despite having thickened septums.

Hypertrophy of the septum occurred in three of seven babies with hypoglycaemia, but in only five of 24 without hypoglycaemia, and in none of the control babies, suggesting an association between neonatal hypoglycaemia and septal thickness. Breitweser et al also showed this association. ${ }^{12}$ In the present series the septal thickness in babies who developed hypoglycaemia did not differ significantly from those without it.

Most earlier studies were on $\mathrm{M}$ mode echocardiographic equipment. It is likely that with only an $M$ mode echo the internal dimensions and thicknesses may not be correctly identified because the echo beam was not absolutely perpendicular. An $M$ mode echo derived from a cross sectional image overcomes this drawback.

The presence of asymmetric septal hypertrophy in the newborn is not specific for any disorder. Normal infants have been reported to have it if the ratio of septum:ventricular posterior wall $>1 \cdot 3$. They can be separated from others because they do not have an absolute increase in septal thickness. It may occur in familial cases, glycogen storage disease (type II), and any cause of right ventricular hypertension. ${ }^{13}{ }^{14}$ In diabetes the hypertrophy may be asymptomatic and regress over months. In Pompe's disease it presents at about 3-4 months of age.

Six of the eight infants with septal hypertrophy had evidence of decreasing septal thickness on serial echocardiograms, confirming the earlier reports of the transient nature of the problem. ${ }^{2} 8$
Any infant born to a diabetic mother who also has respiratory distress must have an echocardiogram because congestive cardiac failure can be the result of obstructive or non-obstructive cardiomyopathy. Whether better control of diabetes in the mother leads to a decreased incidence of cardiac hypertrophy needs to be substantiated.

\section{References}

1 Serrato M, Yeh TS, Harris V, et al. A prospective study on cardiopulmonary findings in infants of diabetic mothers. Riviste Italiana di Pediatrica 1979;5:59-63.

${ }^{2}$ Gutgesell HP, Mullins CE, Gillette PC, et al. Transient hypertrophic subaortic stenosis in infants of diabetic mothers. J Pediatr 1976;89:120-4.

3 Halliday HL. Hypertrophic cardiomyopathy in infants of poorly controlled diabetic mothers. Arch Dis Child 1981;56: 258-63.

${ }^{4}$ Reller MD, Tsang RG, Meyer RA, Baun CP. Relationship of prospective diabetes control in pregnancy to neonatal cardiorespiratory function. J Pediatr 1985;106:86-90.

5 O'Sullivan JB, Mohan CM. Criteria for oral glucose tolerance test in pregnancy. Diabetes 1964;13:278-85.

${ }^{6}$ Singh M. Care of the newborn, 3rd ed. Delhi: Sagar Publications, 1985.

${ }^{7}$ Feigenbaum H. Echocardiography. 2nd ed. Philadeliphia: Lea and Febiger, 1976

${ }^{8}$ Way GL, Wolfe RR, Eshaghpour E, et al. The natural history of hypertrophic cardiomyopathy in infants of diabetic mothers. $J$ Pediatr 1979;95:1020-5.

${ }^{9}$ Bennet DH, Evans DW. Correlation of left ventricular mass determined by echocardiography with vector cardiographic and electrocardiographic voltage measurements. Br Heart J 1974;36: 981-7.

10) Avery Gordon B. Neonatology: pathophysiologyand management of the newborn. 3rd ed. Philadelphia: JB Lippincott, 1987:342-3.

"Maron BJ, Verter J, Kapur S. Disproportionate ventricular septal thickening in the developing normal human heart. Circulation 1978;57:520-6.

12 Breitweser JA, Meyer RA, Speriling MA, Tsang RC, Kaplan S. Cardiac septal hypertrophy in hyperinsulinemic infants. $J$ Pediatr 1980;96:535-9.

13 Maron BJ, Edwards JE, Henery WL, et al. Asymmetric septal hypertrophy in infancy. Circulation 1974;50:809-20.

14 Rees A, Elbl F, Monhas K, et al. Echocardiographic evidence of outflow tract obstruction in Pompe's disease. Am J Cardiol 1976;35:1106-10.

Correspondence to Dr S Shrivastava, Department of Cardiology, All India Institute of Medical Sciences, Ansari Nagar, New Delhi 11029, India.

Accepted 21 October 1988 